CENTRE FOR EMEA BANKING, FINANCE \& ECONOMICS

\title{
INTEREST RATE DYNAMICS IN KENYA: COMMERCIAL BANKS' RATES AND THE 91-DAY TREASURY BILL RATE
}

Guglielmo Maria Caporale and Luis A. Gil-Alana

Working Paper Series

$$
\text { No } 11 / 11
$$




\title{
INTEREST RATE DYNAMICS IN KENYA: COMMERCIAL BANKS' RATES AND THE 91-DAY TREASURY
} BILL RATE

\section{Guglielmo Maria Caporale ${ }^{a}$ Brunel University, London}

\author{
Luis A. Gil-Alana ${ }^{b}$ \\ University of Navarra
}

\begin{abstract}
This paper analyses the implicit dynamics underlying the interest rate structure in Kenya. For this purpose we use data on four commercial banks' interest rates (Deposits, Savings, Lending and Overdraft) together with the 91-Day Treasury Bill rate, for the time period July 1991 - August 2010, and apply various techniques based on long-range dependence and, in particular, on fractional integration. The results indicate that all series examined are nonstationary with orders of integration equal to or higher than 1 . The analysis of various spreads suggests that they also are nonstationary I(1) variables, the only evidence of mean reversion being obtained in the case of the Deposits Treasury Bill rate spread with autocorrelated errors.
\end{abstract}

Keywords: Fractional integration, long-range dependence, interest rates

JEL Classification: $\quad$ C22, G21

${ }^{a}$ Corresponding author: Professor Guglielmo Maria Caporale, Centre for Empirical Finance, Brunel University, West London, UB8 3PH, UK. Tel.: +44 (0)1895 266713. Fax: +44 (0)1895 269770. Email: Guglielmo-Maria.Caporale@brunel.ac.uk

${ }^{\mathrm{b}}$ The second-named author gratefully acknowledges financial support from the Ministerio de Ciencia y Tecnología (ECO2008-03035 ECON Y FINANZAS, Spain) and from a PIUNA Project of the University of Navarra. 


\section{Introduction}

This paper examines the interest rate structure in Kenya. Analysing its stochastic properties can provide useful information about the effects of shocks and appropriate policy responses. Specifically, if the series of interest is stationary I(0) shocks affecting it will have transitory effects, disappearing in the long run. On the contrary, if the series is nonstationary I(1) the effects of shocks will be permanent and policy intervention will become necessary for mean reversion to occur. Therefore, to determine the order of integration of the series is crucial. However, in the case of interest rates the literature is very inconclusive with respect to this matter, finding empirical evidence supporting both stationarity $\mathrm{I}(0)$ and nonstationarity $\mathrm{I}(1)$.

Interest rates play a key role in two very important relationships in macroeconomics, i.e., the Fisher hypothesis (FH) and uncovered interest rate parity (UIP). The former links nominal rates to expected inflation, requiring full adjustment of these two variables in the long run and implying stationary $\mathrm{I}(0)$ of ex-ante interest rates (a crucial variable for understanding investment and saving decisions as well as asset price determination). In the absence of a one-to-one adjustment, permanent shocks to either inflation or nominal rates would have permanent effects on real rates as well, which would be inconsistent with standard models of intertemporal asset pricing. If interest rates and inflation are found to be nonstationary I(1) processes, a long-run version of the FH can be tested within a cointegration framework (Mishkin, 1992). As for UIP, I(0) stationarity of nominal short-run interest rates is required for its empirical validity. Since nominal bilateral exchange rates are difference-stationary, for the UIP relation to hold nominal short-run interest rates must be mean-reverting. Previous empirical studies conclude that short-run interest rates are in fact meanreverting in Europe and in the US (e.g. Rose, 1988; Stock and Watson, 1988; Wu and Chen, 2001), providing support for the UIP relationship but not for the long-run FH. The implication for monetary policy is that central banks are constrained in their ability to set interest rates by international capital flows. In the case of the African countries such issues are even more important since their 
financial markets are characterised by a high level of information asymmetry and their central banks are not perceived by markets as having credibility.

The present study analyses the implicit dynamics underlying the interest rate structure in Kenya. For this purpose we use data on four commercial banks' interest rates (Deposits, Savings, Lending and Overdraft) together with the 91-Day Treasury Bill rate, for the time period July 1991 August 2010. However, instead of carrying out standard tests based on the dichotomy between stationarity $I(0)$ or nonstationarity I(1), we use techniques based on long-range dependence and, in particular, on fractional integration that allow for non-integer degrees of differentiation.

The outline of the paper is as follows. Section 2 briefly reviews the literature on interest rate models with I(d) variables, including some studies on African countries. Section 3 outlines the econometric approach employed for the analysis. Section 4 describes the data and presents the univariate results, whilst Section 5 focuses on the spreads. Section 6 offers some concluding remarks.

\section{Literature review}

A variety of interest rate models have been suggested in the literature. The crucial issue is to determine the order of integration of the series, namely whether interest rates are stationary $I(0)$ (and thus mean-reverting) or nonstationary I(1). Some studies have investigated the mean reversion property of interest rates in the context of fixed income modelling - see, for example, the papers by Chapman and Pearson (2000), Jones (2003), Bali and Wu (2006), and Koutmos and Philappatos (2007) among others.

In the last two decades more attention has been paid to the possibility of long memory in interest rates. For instance, Shea (1991) investigated this issue in the context of the expectations hypothesis of the term structure. He found that allowing for the possibility of long memory significantly improves the performance of the model, even though the expectations hypothesis cannot be fully resurrected. In related work, Backus and Zin (1993) observed that the volatility of 
bond yields does not decline exponentially when the maturity of the bond increases; in fact, they noticed that the decline was hyperbolic, consistently with the fractionally integrated specification. Lai (1997) and Phillips (1998) provided evidence based on semiparametric methods that ex-ante and ex-post US real interest rates are fractionally integrated. Tsay (2000) employed an ARFIMA model and concluded that the US real interest rate can be described as an I(d) process. Further evidence can be found in Barkoulas and Baum (1997), Meade and Maier (2003) and Gil-Alana (2004a, b). Couchman, Gounder and Su (2006) estimated ARFIMA models for ex-post and ex-ante interest rates in sixteen countries. Their results suggest that, for the majority of countries, the fractional differencing parameter lies between 0 and 1 , and is considerably smaller for the ex-post than for the ex-ante rates.

Only a few studies on African countries exist. Nandwa (2006) examined whether nominal interest rates in a sample of Sub-Saharan countries follow stochastic trends (or unit root processes) and whether the Fisher hypothesis holds in the area. More recently, Aboagye et al. (2008) investigated the question of the optimal spread between bank lending rates and rates that banks pay on deposits in Ghana. They found that increases in bank market power, bank size, staff costs among other factors significantly increase net interest margins, while increases in bank excess cash reserves and central bank lending rate decrease them. More evidence is available in the case of Kenya. Elliott, Kwack and Tavlas (1986) estimated an econometric model for this country including interest rates. Musila (2002) applied cointegration methods to develop a macro model for forecasting purposes. Ndung'u (2000) examined the relationship between exchange rates and interest rate differentials in Kenya using a time-varying parameters approach. Finally, in a more recent paper, Odhiambo (2009) investigated the impact of interest rate reforms on financial deepening and economic growth in Kenya. He found a positive relationship in both cases using standard $(I(0) / I(1))$ cointegration techniques.

\section{Econometric Methodology}


As already mentioned we employ methods based on long-range dependence. In particular we focus our attention on fractionally integrated or $\mathrm{I}(\mathrm{d})$ models. A time series $\left\{\mathrm{x}_{\mathrm{t}}, \mathrm{t}=1,2, \ldots\right\}$ is said to be fractionally integrated of order $d$, and denoted by $x_{t} \sim I(d)$ if it can be represented as

$$
(1-L)^{d} x_{t}=u_{t}, \quad t=1,2, \ldots
$$

where $L$ is the lag-operator $\left(L x_{t}=x_{t-1}\right)$ : $\mathrm{d}$ can be any real value, and $\mathrm{u}_{\mathrm{t}}$ is an $\mathrm{I}(0)$ process, being defined as a covariance stationary process with a spectral density function that is positive and finite at any frequency. This includes a wide range of model specifications such as the white noise, the stationary autoregression (AR), moving average (MA), stationary ARMA etc.

The polynomial appearing on the left hand side in equation (1) can be defined in terms of its Binomial expansion

$$
(1-L)^{d}=\sum_{j=0}^{\infty} \frac{\Gamma(j-d)}{\Gamma(j+1) \Gamma(-d)} L^{j}
$$

where $\Gamma(x)$ is the Gamma function. It is also well known that the autocovariance function of this process $\left(\gamma_{u}\right)$ satisfies:

$$
\gamma_{u} \approx c_{1} u^{2 d-1}, \text { as } \mathrm{j} \rightarrow \infty, \text { for }\left[\mathrm{C}_{1} \text { 回 }<\infty,\right.
$$

and, assuming that $\mathrm{x}_{\mathrm{t}}$ has an absolute continuous spectral distribution function, so that it has a spectral density function $f(\lambda)$, defined as

$$
f(\lambda)=\frac{1}{2 \pi}\left(\gamma_{0}+2 \sum_{u=1}^{\infty} \gamma_{u} \cos (\lambda u)\right)
$$

it can also be proved that

$$
f(\lambda) \approx c_{2} \lambda^{-2 d}, \text { as } \lambda \rightarrow 0^{+}, \text {for } 0<c_{2}<\infty \text {, }
$$

where the symbol " $\approx$ " indicates that the ratio of the left-hand side and the right-hand side tends to 1 , as $\mathrm{j} \rightarrow \infty$ in (2) and as $\lambda \rightarrow 0^{+}$in (3) (see Granger and Joyeux, 1980; Hosking (1981), Brockwell and Davis, 1993; Baillie, 1996; etc.).

\footnotetext{
${ }^{1}$ Conditions (2) and (3) are not always equivalent but Zygmund (1995) and, in a more general case, Yong (1974) both give conditions under which both expressions are equivalent.
} 
When $d=0$ in (1), $x_{t}=u_{t}$, and therefore $x_{t}$ is $\mathrm{I}(0)$, and possibly "weakly autocorrelated" (also known as "weakly dependent"), with the autocorrelations decaying exponentially if the underlying disturbances are autoregressive. If $0<\mathrm{d}<0.5, \mathrm{x}_{\mathrm{t}}$ is still stationary, but its lag-u autocovariance $\gamma_{\mathrm{u}}$ decreases very slowly, in fact hyperbolically, according to equation (2), and therefore the $\gamma_{u}$ are absolutely non-summable. In that case $x_{t}$ is said to exhibit long memory given that its spectral density $f(\lambda)$ is unbounded at the origin (see equation (3)). Finally, it is important to note that as $d$ in (1) increases beyond 0.5 and towards 1 (the unit root case), $x_{t}$ can be viewed as becoming "more nonstationary" in the sense, for example, that the variance of the partial sums increases in magnitude. This is also true for $d>1$, so a large class of nonstationary processes may be described by (1) with $d \geq 0.5^{2}$

The method employed in this paper to estimate the fractional differencing parameter $d$ is based on the Whittle function in the frequency domain (Dahlhaus, 1989) along with a testing Lagrange Multiplier (LM) procedure developed by Robinson (1994) that allows to test the null hypothesis $H_{0}: d=d_{0}$ in equation (1) for any real value $d_{0}$, where $x_{t}$ can be the errors in a regression model of the form:

$$
y_{t}=\beta^{T} z_{t}+x_{t}, \quad t=1,2, \ldots,
$$

where $y_{t}$ is the observed time series, $\beta$ is a (kx1) vector of unknown coefficients and $z_{t}$ is a set of deterministic terms that might include an intercept (i.e., $z_{t}=1$ ), an intercept with a linear time trend $\left(z_{t}=(1, t)^{\top}\right)$, or any other type of deterministic processes. Although there exists more recent procedures to estimate parametrically $d$ either in the time or in the frequency domain (Lobato and Velasco, 2007; Demetrescu, Kuzin and Hassler, 2008), they generally require an efficient estimate of $d$, and therefore the LM test of Robinson (1994) seems computationally more attractive. A semiparametric approach devised by Robinson (1995) will also be applied here; although other versions of this method have been suggested (Velasco, 1999; Velasco and Robinson, 2000; Phillips

\footnotetext{
${ }^{2}$ See Diebold and Rudebusch (1989), Sowell (1992a) and Gil-Alana and Robinson (1997) for applications involving $\mathrm{I}(\mathrm{d})$ processes in macroeconomic time series.
} 
and Shimotsu, 2004; Shimotsu and Phillips, 2005; Abadir et al., 2007), they require additional userchosen parameters, with the estimates of $d$ possibly being very sensitive to the choice of these parameters. In this respect, the method of Robinson (1995), which is computationally simpler, seems preferable. $^{3}$

\section{Data and empirical results}

The series used are from the Central Bank of Kenya database and can be downloaded from: http://www2.centralbank.go.ke/downloads/index.htm. Their frequency is monthly, and the sample goes from July 1991 to March 2009. The series are the commercial banks' weighted average interest rates for Deposit, Savings, Lending and Overdraft, and the 91-day Treasury bill rate.

\section{[Insert Figure 1 about here]}

We start by considering a model of the form given by equations (1) and (4) with $z_{t}=(1, t)^{\top}$, i.e.,

$$
y_{t}=\alpha+\beta t+x_{t} ; \quad(1-L)^{d} x_{t}=u_{t}, \quad t=1,2, \ldots
$$

assuming first that the error term $\mathrm{u}_{\mathrm{t}}$ is white noise and then that it is autocorrelated. In the latter case, we assume that $u_{t}$ follows the exponential spectral model of Bloomfield (1973). This is a nonparametric approach that produces autocorrelations decaying exponentially as in the $A R(M A)$ case. Its main advantage is that it mimics the behaviour of ARMA structures with a small number of

\footnotetext{
${ }^{3}$ In additionally to the methods discussed in the text, we also employed other conventional parametric approaches such as Sowell's (1992b) and Beran's (1995) maximum likelihood methods and the results were completely in line with those reported in the paper.
} 
parameters. Moreover, it is stationary independently of the values of its coefficients unlike in the AR case. $^{4}$

For each series, we consider the three standard cases examined in the literature, i.e., no regressors (i.e., $\alpha=\beta=0$ a priori in (5)), an intercept ( $\alpha$ unknown and $\beta=0$ a priori), and an intercept with a linear time trend (i.e., $\alpha$ and $\beta$ unknown). Table 1 reports the (Whittle) estimates of $d$ under the assumption of white noise errors. Table 2 refers to the exponential model of Bloomfield (1973). In both cases we display along with the estimates the $95 \%$ confidence interval of the non-rejection values of d using Robinson's (1994) parametric approach.

\section{[Insert Tables 1 and 2 about here]}

Starting with the results based on white noise disturbances, it can be seen that the estimates of $d$ are above 1 in all cases, and the unit root null hypothesis is practically always rejected; the only exceptions are "Savings" and "Overdraft" when deterministic terms are not included in the model. Concerning the specification with an intercept (which is the most data congruent in view of the tvalues of the time trend coefficients, not reported), the estimated values of $d$ range between 1.147 (for "Savings") and 1.881 (for the "91-day Treasury Bill rate"). As for the case of autocorrelated (Bloomfield) errors (in Table 2), the results are fairly similar to those displayed in Table 1 with the exception of the "Treasury Bill rate". For this series, the estimated value of $d$ is found to be below 1 , although the unit root null cannot be rejected. For the remaining four series, $d$ is strictly above 1 in practically all cases.

To corroborate the above results, we also implement a semiparametric approach to estimate d that is due to Robinson (1995). This is a "local estimator" in the frequency domain, based on a band of frequencies that degenerates to zero. It is implicitly defined by:

\footnotetext{
${ }^{4}$ See Gil-Alana (2004c) for the advantages of the model of Bloomfield (1973) in the context of Robinson's (1994) tests.
} 


$$
\begin{gathered}
\hat{d}=\arg \min _{d}\left(\log \overline{C(d)}-2 d \frac{1}{m} \sum_{j=1}^{m} \log \lambda_{j}\right), \\
\text { for } d \in(-1 / 2,1 / 2) ; \quad \overline{C(d)}=\frac{1}{m} \sum_{j=1}^{m} I\left(\lambda_{j}\right) \lambda_{j}^{2 d}, \quad \lambda_{j}=\frac{2 \pi j}{T}, \quad \frac{1}{m}+\frac{m}{T} \rightarrow 0,
\end{gathered}
$$

where $m$ is the bandwidth parameter, and $\mathrm{I}\left(\lambda_{\mathrm{j}}\right)$ is the periodogram of the time series, $\mathrm{x}_{\mathrm{t}}$, given by:

$$
\mathrm{I}\left(\lambda_{\mathrm{j}}\right)=\frac{1}{2 \pi \mathrm{T}}\left|\sum_{\mathrm{t}=1}^{\mathrm{T}} \mathrm{x}_{\mathrm{t}} \mathrm{e}^{\mathrm{i} \lambda_{\mathrm{j}} \mathrm{t}}\right|^{2}
$$

Under finiteness of the fourth moment and other mild conditions, Robinson (1995) proved that:

$$
\sqrt{\mathrm{m}}\left(\hat{\mathrm{d}}-\mathrm{d}_{\mathrm{o}}\right) \rightarrow_{\mathrm{d}} \mathrm{N}(0,1 / 4) \quad \text { as } \mathrm{T} \rightarrow \infty
$$

where $d_{o}$ is the true value of $d$ and with the only additional requirement that $m \rightarrow \infty$ slower than T.

\section{[Insert Figure 2 about here]}

The results based on the above approach are displayed in Figure 2. Given the nonstationary nature of the series examined, the values are estimated using first- differenced data, then adding 1 to obtain the proper orders of integration of the series. It can be seen that the values are similar for the four series. Along with the estimates we also present the $95 \%$ confidence band corresponding to the I(1) hypothesis. We display the estimates for the whole range of values of the bandwidth parameter $\mathrm{m}(=1,2, \ldots \mathrm{T} / 2)$. Most of them are above the I(1) interval, and there is evidence of $\mathrm{I}(1)$ behaviour only for small values of $\mathrm{m}^{5}$

\section{[Insert Table 3 about here]}

\footnotetext{
${ }^{5}$ When choosing the bandwidth there is a trade-off between bias and variance: the asymptotic variance is decreasing whilst the bias is increasing with $\mathrm{m}$.
} 
Table 3 displays the estimate of $d$ for specific bandwidth parameters, in particular for $m=5$, $10,15\left(=\mathrm{T}^{0.5}\right), 25,50$ and 100 . The unit root null is rejected in the majority of cases in favour of higher orders of integration and there is no single case with evidence of mean reversion. Thus, the results presented so far strongly support the view that the interest rates and T-bill series examined are not mean-reverting, with orders of integration equal to or higher than 1 . Therefore, in the event of exogenous shocks policy intervention will be necessary to bring interest rates back to their original levels since the series will not return by themselves to their mean values.

\section{Analysing the spreads}

In this section we focus on the spreads, and in particular we examine the following differences: Lending - 91 Day Treasury Bill rate; Lending - Saving rate; Deposit - 91 Day Treasury Bill rate, Saving - 91 Day Treasury Bill rate, and Deposits - Lending (see Figure 3). As Treasury bills are generally considered risk-free, T-bill spreads can be seen as an indication of the perceived risk of default, whilst the spread between deposit and lending rates provides some information about banks' profit margins. On the other hand, the spread Lending - Saving may be considered as an approximate measure for the bank's interest margins. Finally, Deposits - Lending rate spreads are clearly related to the banking sector's ability to channel savings into productive uses.

\section{[Insert Figure 3 and Tables 4 and 5 about here]}

Tables 4 and 5 report the estimates for the two cases of white noise and autocorrelated (with Bloomfield) errors respectively. Starting with the case of uncorrelated errors (Table 4), it can be seen that the estimates of $d$ are extremely large (around 1.8) for three of the spreads (Lending Treasury Bill; Deposit - Treasury Bill; and Saving - Treasury Bill), and around 1 (with the unit root not being rejected) for the Lending - Saving, and Deposits - Lending spreads. However, in the more realistic case of autocorrelated errors, the values are much smaller; the unit root cannot be rejected 
for Lending - Treasury Bill, Lending - Saving, Saving - Treasury Bill and Deposits - Lending, and evidence of mean reversion (i.e., orders of integration strictly smaller than 1 ) is only found in the case of the Deposits - Treasury Bill rate spread.

The results for the spreads based on the semiparametric estimation method of Robinson (1995) are displayed in Figure 4. It can be clearly seen that mean reversion does not occur, the estimated values of $d$ being strictly above 1 for most series, especially if the bandwidth parameter is large. Table 6 shows the estimates for specific bandwidth parameters confirming that there is no evidence of mean reversion in any single case. Overall, the structure of interest rates in Kenya is found to display a high degree of persistence, implying the need for policy actions to make markets more flexible and competitive.

\section{[Insert Figure 4 and Table 6 about here]}

\section{Conclusions}

This paper has investigated the interest rate structure in Kenya using procedures based on longrange dependence. In particular, it has examined the orders of integrations of four commercial banks' interest rates (Deposits, Savings, Lending and Overdraft) along with the 91-Day Treasury Bill rate for the period July, 1991 - August, 2010. The results strongly reject the hypothesis of mean reversion in the individual series, their orders of integration being estimated to be equal to or higher than 1 in all cases. The evidence for the spreads is similar, mean reversion being found only in the case of the Deposits - Treasury Bill rate spread under the assumption of autocorrelated errors. The implication of these results is that policies will need to be implemented to achieve mean reversion of interest rates. 


\section{References}

Abadir, K.M., W. Distaso and L. Giraitis, 2007, Nonstationarity-extended local Whittle estimation, Journal of Econometrics 141, 1353-1384.

Aboagye, A.Q.Q., S.K. Akoena, T.O. Antwi-Asare and A.F. Gockel, 2008, Explaining interest rate spreads in Ghana, African Development Review 20, 3, 378-399.

Backus, D. and S. Zin (1993) Long memory inflation uncertainty. Evidence from the term structure of interest rates. Journal of Money, Credit and Banking 25, 681-700.

Baillie, R.T. (1996) Long memory processes and fractional integration in econometrics. Journal of Econometrics 73, 5-59.

Bali, G.T. an Wu, L. 2006. A comprehensive analysis of the short-term interest-rate dynamics, Journal of Banking \& Finance, 30, 1269-1290.

Barkoulas, J.T. and C.F. Baum (1997) Fractional differencing modeling and forecasting of eurocurrency deposit rates. The Journal of Financial Research 20, 355-372.

Beran, J., 1995, Maximum likelihood estimation of the differencing parameter for invertible short and long memory autoregressive integrated moving average models, Journal of the Royal Statistical Society B, 57, 659-672.

Bloomfield, P., 1973, An exponential model in the spectrum of a scalar time series, Biometrika 60, 217-226.

Brockwell, P. and R. Davis, 1993, Time Series, Theory and Methods, $2^{\text {nd }}$ Edition, SpringerVerlag, New York.

Chapman, D.A. and Pearson, N.D. 2000. Is the short rate drift actually nonlinear? Journal of Finance, 55, 355-388.

Couchman, J., R. Gounder and J.J. Su (2006) Long memory properties of real interest rates for 16 countries. Applied Financial Economics Letters 2, 25-30.

Dahlhaus, R. (1989) Efficient parameter estimation for self-similar process. Annals of Statistics 17, $1749-1766$. 
Demetrescu, M., V. Kuzin and U. Hassler, 2008, Long memory testing in the time domain, Econometric Theory 24, 176-215.

Diebold, F.X. and G.D. Rudebusch (1989) Long memory and persistence in the aggregate output. Journal of Monetary Economics 24, 189-209.

Elliott, J., S.Y. Kwack and George S. Tavlas, 1986, An econometric model for the Kenyan economy, Economic Modelling 3, 1, 2-30.

Gil-Alana, L.A. (2004a) Long memory in the interest rates in some Asian countries. International Advances in Economic Research 9, 257-267.

Gil-Alana, L.A. (2004b) Long memory in the US interest rate. International Review of Financial Analysis 13, 265-276.

Gil-Alana, L.A (2004c) The use of the model of Bloomfield as an approximation to ARMA processes in the context of fractional integration, Mathematical and Computer Modelling 39, 429-436.

Gil-Alana, L.A. and P.M. Robinson (1997) Testing of unit roots and other nonstationary hypotheses in macroeconomic time series. Journal of Econometrics 80, 241-268.

Granger, C.W.J. and R. Joyeux, 1980, An introduction to long memory time series and fractionally differencing, Journal of Time Series Analysis 1, 15-29.

Hosking, J.R.M., 1981, Fractional differencing, Biometrika 68, 168-176.

Jones, C.S. 2003. Nonlinear mean reversion in the short-term interest rate, Review of Financial Studies 16, 793-843.

Koutmos, G. and Philappatos, G.C. 2007. Asymmetric Mean Reversion in European Interest Rates: A Two-fsactor Model, The European journal of Finance 13, 741-750.

Lai, K.S. (1997) Long term persistence in real interest rate. Some evidence of a fractional unit root. International Journal of Finance and Economics 2, 225-235.

Lobato, I. and C. Velasco, 2007, Efficient Wald tests for fractional unit roots, Econometrica $75,575-589$. 
Meade, N. and M.R. Maier (2003) Evidence of long memory is short term interest rates. Journal of Forecasting 22, 553-568.

Mishkin, F.S. (1992), Is the Fisher effect for real? A re-examination of the relationship between inflation and interest rates, Journal of Monetary Economics 30, 195-215.

Musila, Jacob W., 2002, A forecasting model of the Kenyan economy, Economic Modelling $19,5,801-814$.

Nandwa. B., 2006, On the Fisher effect and inflation dynamics in low income countries. An assessment of Sub-Saharan African economies, Applied Econometrics and International Development 6, 1 .

Ndung'u, N. (2000) The exchange rate and the interest rate differential in Kenya: A monetary and fiscal policy dilemma, Kenya Institute for Public Policy Research and Analysis, KIPPRA Discussion Paper No.1

Odhiambo, Nicholas M. (2009), Interest rate reforms, financial deepening and economic growth in Kenya. An empirical investigation, The Journal of Developing Areas 43, 1.

Phillips, P.C.B. (1998) Econometric analysis of Fisher's equation, Yale University, Cowles Foundation Discussion Paper 1180.

Phillips, P.C.B. and Shimotsu, K., 2004. Local Whittle estimation in nonstationary and unit root cases. Annals of Statistics 32, 656-692.

Robinson, P.M. (1994). Efficient tests of nonstationary hypotheses. Journal of the American Statistical Association, 89, 1420-1437.

Robinson, P.M., 1995. Gaussian semiparametric estimation of long range dependence. Annals of Statistics 23, 1630-1661.

Rose, A., 1988. Is the real interest rate stable? Journal of Finance 43, 1095-1112.

Shea, G. (1991), Uncertainty and implied variance bounds in long memory models of the interest rate term structure. Empirical Economics 16, 287-312. 
Shimotsu, K. and P.C.B. Phillips, 2005. Exact local Whittle estimation of fractional integration. Annals of Statistics 33, 1890-1933.

Sowell, F. (1992a) Modelling long run behaviour with the fractional ARIMA model. Journal of Monetary Economics 29, 277-302.

Sowell, F. (1992b) Maximum likelihood estimation of stationary univariate fractionally integrated time series models. Journal of Econometrics 53, 165-188.

Stock, J.H. and Watson, M.W., 1988. Testing for common trends. Journal of the American Statistical Association 83, 1097-1107.

Tsay, W.J. (2000) The long memory story of the real interest rate. Economics Letters 67, 325-330.

Velasco, C. (1999) Gaussian semiparametric estimation of nonstationary time series. Journal of Time Series Analysis 20, 87-127.

Velasco, C. and P.M. Robinson, 2000, Whitle pseudo maximum likelihood estimation for nonstationary time series. Journal of the American Statistical Association 95, 1229-1243.

Wu, J.L. and Chen, S.L. 2001. Mean reversion of interest rates in the Eurocurrency market. Oxford Bulletin of Economics and Statistics 63, 459-473.

Yong, C.H., 1974, Asymptotic behaviour of trigonometric time series, Hong Kong, Chinese University of Hong Kong.

Zygmund, A., 1995, Trigonometric series, Cambridge University Press, Cambridge. 
Figure 1: Time series plots of the commercial bank's weighted average interest rates and the 91day Treasury Bill rate

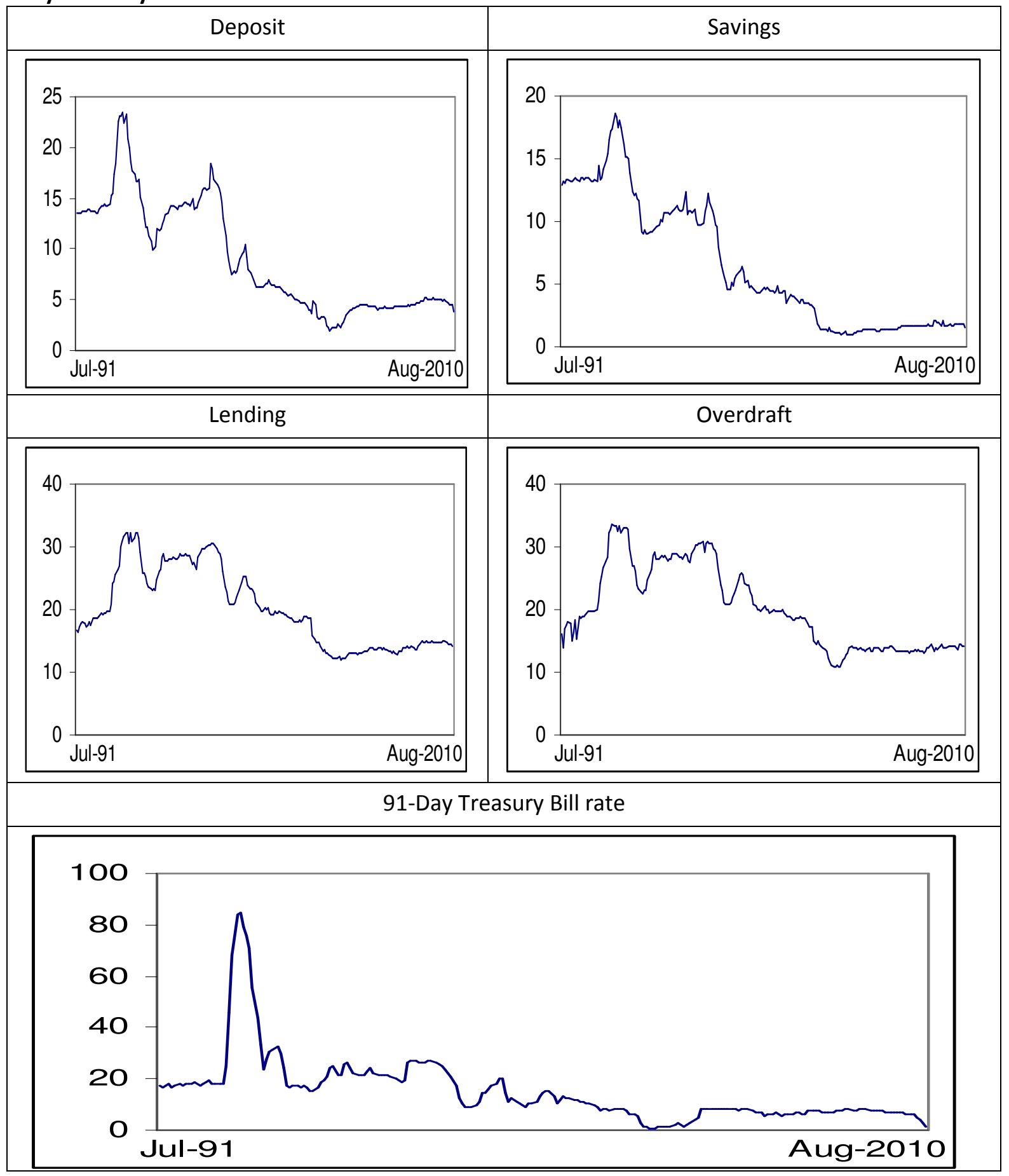


Figure 2: Estimates of $d$ based on the semiparametric method of Robinson (1995)

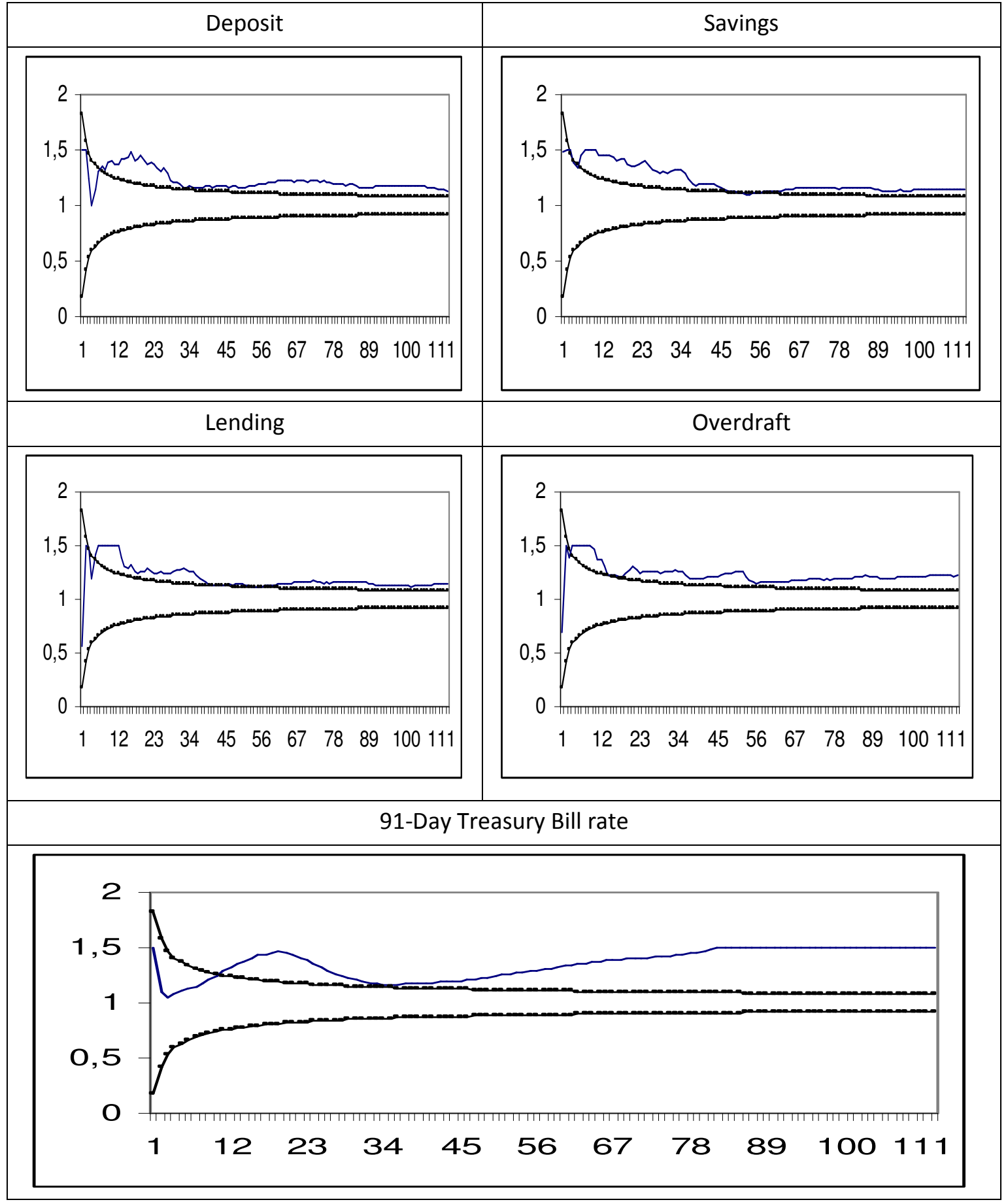

The horizontal axis refers to the bandwidth parameter, while the vertical one reports the estimated value of $d$. 
Figure 3: Time series plots of the spreads

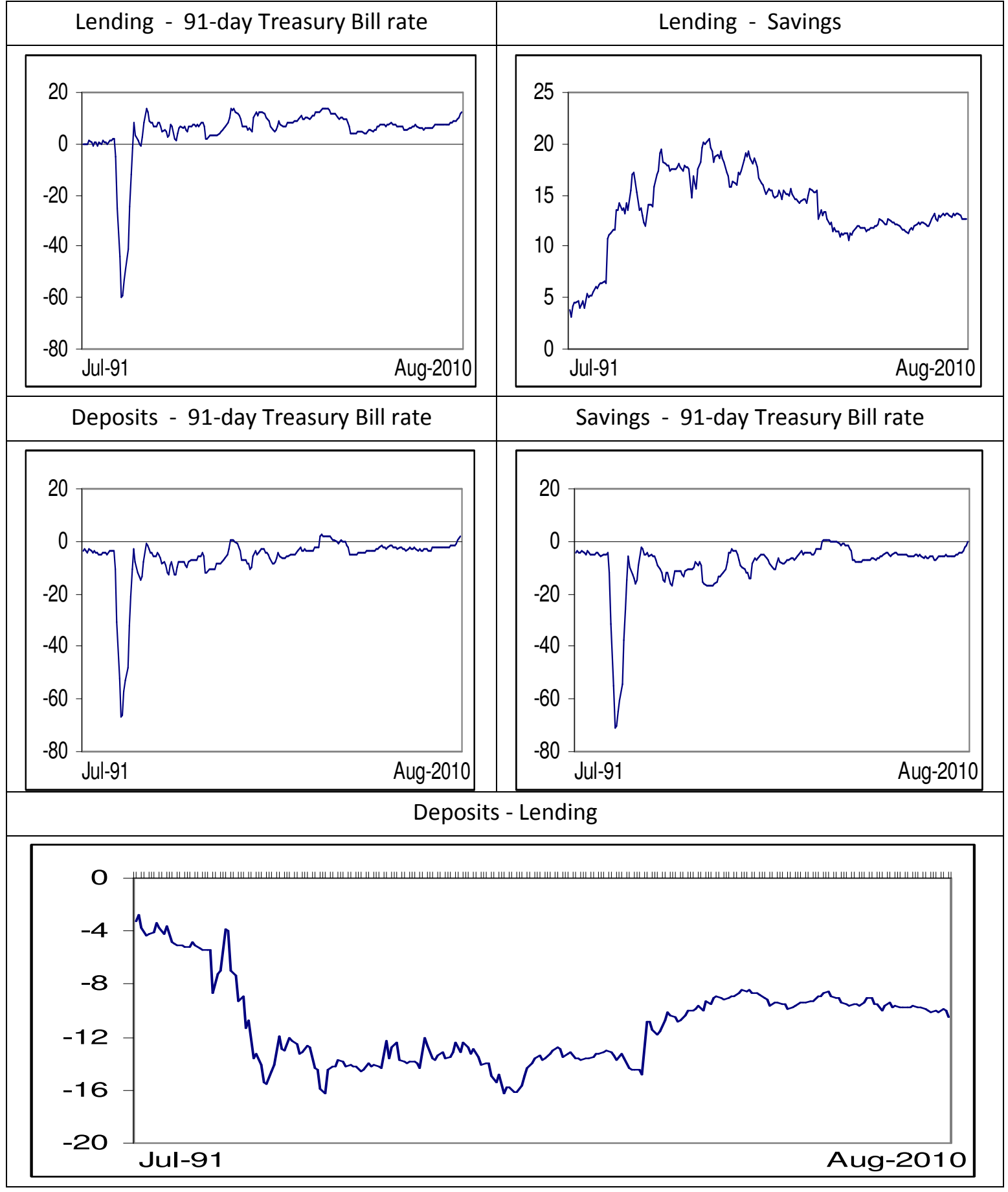


Figure 4: Estimates of $d$ for the spreads based on Robinson (1995)

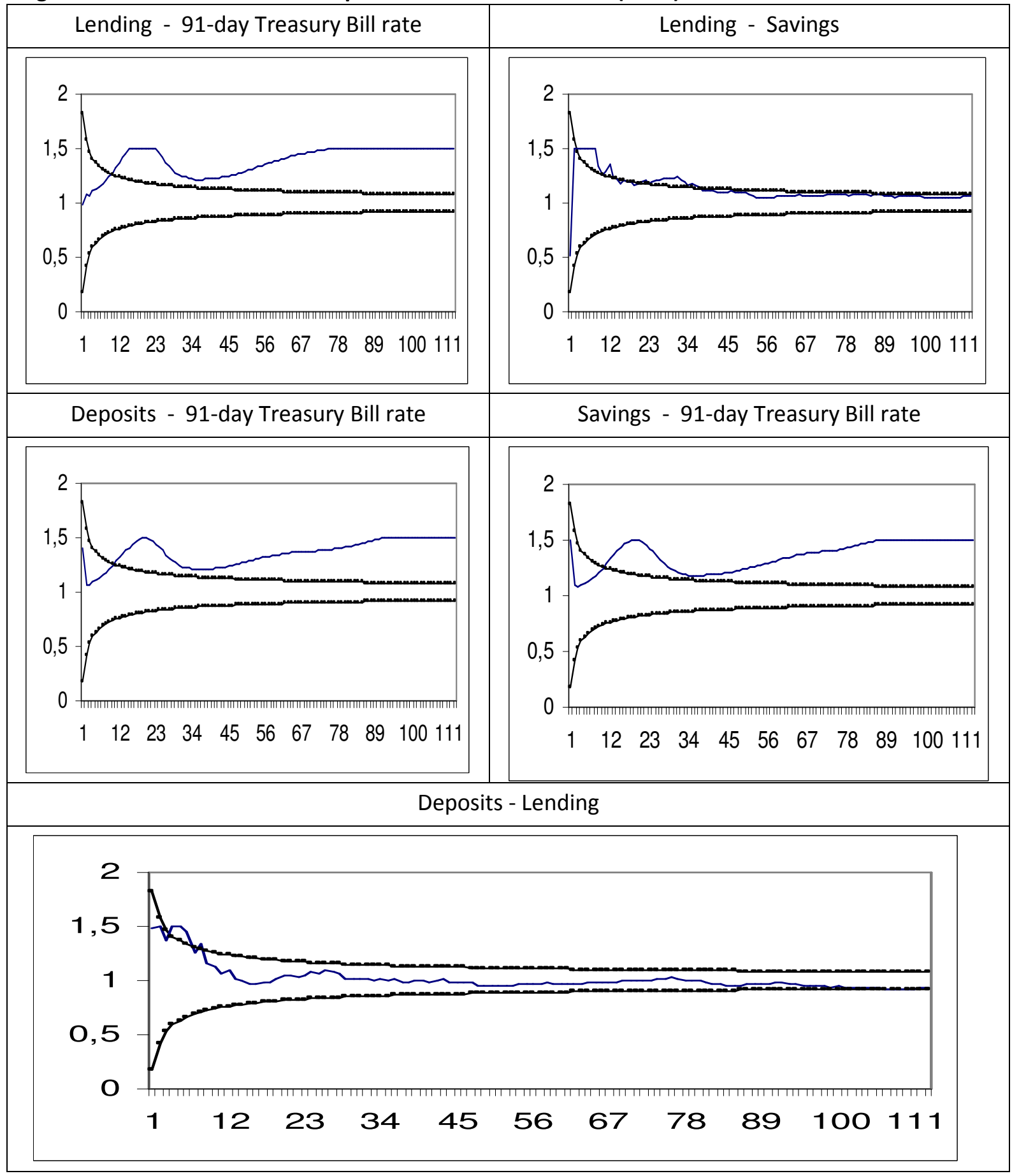

The horizontal axis refers to the bandwidth parameter, while the vertical one reports the estimated value of $d$. 
Table 1: Estimates of $d$ based on Robinson (1994) using white noise disturbances

\begin{tabular}{|c|c|c|c|}
\hline & No regressors & An intercept & A linear time trend \\
\hline Deposits & $\begin{array}{c}1.082 \\
(1.007,1.180)\end{array}$ & $\begin{array}{c}1.311 \\
(1.224,1.416)\end{array}$ & $\begin{array}{c}1.311 \\
(1.224,1.416)\end{array}$ \\
\hline Savings & 1.039 & 1.147 & 1.147 \\
& $(0.967,1.135)$ & $(1.069,1.245)$ & $(1.069,1.245)$ \\
\hline Lending & 1.090 & 1.292 & 1.291 \\
& $(1.019,1.184)$ & $(1.207,1.399)$ & $(1.206,1.398)$ \\
\hline Overdraft & 1.049 & 1.158 & 1.158 \\
& $(0.988,1.128)$ & $(1.084,1.252)$ & $(1.084,1.251)$ \\
\hline 91-day Treasury Bill & 1.651 & 1.881 & 1.881 \\
& $(1.482,1.851)$ & $(1.679,2.121)$ & $(1.679,2.121)$ \\
\hline
\end{tabular}

The reported values are Whittle estimates of $d$ in the frequency domain. Those in parentheses are the $95 \%$ confidence intervals of non-rejection values of d using Robinson's (1994) tests.

Table 2: Estimates of $d$ based on Robinson (1994) using Bloomfield disturbances

\begin{tabular}{|c|c|c|c|}
\hline & No regressors & An intercept & A linear time trend \\
\hline Deposits & $\begin{array}{c}1.110 \\
(0.967,1.308)\end{array}$ & $\begin{array}{c}1.429 \\
(1.179,1.750)\end{array}$ & $\begin{array}{c}1.429 \\
(1.179,1.751)\end{array}$ \\
\hline Savings & 1.039 & 1.228 & 1.228 \\
& $(0.923,1.231)$ & $(1.038,1.501)$ & $(1.038,1.501)$ \\
\hline Lending & 1.138 & 1.308 & 1.322 \\
& $(1.004,1.337)$ & $(1.112,1.588)$ & $(1.112,1.587)$ \\
\hline Overdraft & 1.260 & 1.308 & 1.308 \\
& $(1.102,1.530)$ & $(1.114,1.570)$ & $(1.114,1.568)$ \\
\hline 90-day Treasury Bill & 0.909 & 0.759 & 0.751 \\
& $(0.710,1.242)$ & $(0.563,1.101)$ & $(0.525,1.101)$ \\
\hline
\end{tabular}

The reported values are Whittle estimates of $d$ in the frequency domain. Those in parentheses are the $95 \%$ confidence intervals of non-rejection values of d using Robinson's (1994) tests. 
Table 3: Estimates of $d$ based on Robinson (1995) for various bandwidth parameter values

\begin{tabular}{|c|c|c|c|c|c|c|}
\hline & 5 & 10 & $15=\mathrm{T}^{0.5}$ & 25 & 50 & 100 \\
\hline Deposits & $1.152^{*}$ & 1.402 & 1.434 & 1.314 & $1.160^{*}$ & 1.183 \\
\hline Savings & $1.338^{*}$ & 1.500 & 1.435 & 1.358 & 1.119 & 1.143 \\
\hline Lending & 1.424 & 1.500 & 1.295 & 1.253 & $1.140^{*}$ & 1.123 \\
\hline Overdraft & 1.500 & 1.373 & 1.219 & 1.262 & 1.261 & 1.203 \\
\hline $\begin{array}{c}\text { 91-day Treasury Bill } \\
\text { 95\% Confidence } \\
\text { Interval }\end{array}$ & $\begin{array}{c}1.108^{*} \\
1.7367)\end{array}$ & 1.243 & 1.403 & 1.325 & 1.241 & 1.500 \\
\hline
\end{tabular}

"* " indicates that the null hypothesis of a unit root cannot be rejected at the $5 \%$ level. 
Table 4: Estimates of d based on Robinson (1994) using white noise disturbances

\begin{tabular}{|c|c|c|c|}
\hline & No regressors & An intercept & A linear time trend \\
\hline Lending - 91 T Bill & $\begin{array}{c}1.815 \\
(1.628,2.032)\end{array}$ & $\begin{array}{c}1.815 \\
(1.629,2.032)\end{array}$ & $\begin{array}{c}1.815 \\
(1.629,2.032)\end{array}$ \\
\hline Lending - Saving & $\begin{array}{c}1.006 \\
(0.943,1.089)\end{array}$ & $\begin{array}{c}1.006 \\
(0.941,1.006)\end{array}$ \\
\hline Deposit - 91 T Bill & 1.815 & 1.833 & $(0.943,1.091)$ \\
\hline Saving - 91 T Bill & $(1.605,2.066)$ & $(1.619,2.088)$ & $(1.619,2.088)$ \\
\hline \multirow{2}{*}{ Deposits - Lending } & 1.832 & 1.855 & 1.856 \\
& $(0.875,1.020)$ & $(1.656,2.092)$ & $(1.656,2.092)$ \\
\hline
\end{tabular}

The reported values are Whittle estimates of $d$ in the frequency domain. Those in parentheses refer to the $95 \%$ confidence intervals of the non-rejection values of d using Robinson's (1994) tests.

Table 5: Estimates of d based on Robinson (1994) using Bloomfield disturbances

\begin{tabular}{|c|c|c|c|}
\hline & No regressors & An intercept & A linear time trend \\
\hline Lending - 91 T Bill & 0.793 & 0.794 & 0.786 \\
& $(0.519,1.175)$ & $(0.525,1.176)$ & $(0.523,1.176)$ \\
\hline Lending - Saving & 1.113 & 1.108 & 1.098 \\
& $(0.993,1.324)$ & $(0.978,1.308)$ & $(0.979,1.297)$ \\
\hline Deposit - 91 T Bill & 0.793 & 0.599 & 0.579 \\
& $(0.519,1.175)$ & $(0.371,0.930)$ & $(0.327,0.931)$ \\
\hline Saving - 91 T Bill & 0.728 & 0.711 & 0.711 \\
& $(0.511,1.086)$ & $(0.456,1.039)$ & $(0.452,1.039)$ \\
\hline Deposits - Lending & 1.027 & 0.994 & 0.994 \\
& $(0.911,1.182)$ & $(0.872,1.157)$ & $(0.884,1.146)$ \\
\hline
\end{tabular}

The reported values are Whittle estimates of $d$ in the frequency domain. Those in parentheses refer to the $95 \%$ confidence intervals of the non-rejection values of d using Robinson's (1994) tests. 
Table 6: Estimates of $d$ in the spreads based on Robinson (1995) for various bandwidth parameter values

\begin{tabular}{|c|c|c|c|c|c|c|}
\hline & 5 & 10 & $15=\mathrm{T}^{0.5}$ & 25 & 50 & 100 \\
\hline Lending - 91 T Bill & $1.129^{*}$ & 1.277 & 1.500 & 1.419 & 1.290 & 1.500 \\
\hline Lending - Saving & 1.500 & 1.296 & $1.184^{*}$ & 1.202 & $1.092^{*}$ & $1.047^{*}$ \\
\hline Deposit - 91 T Bill & $1.110^{*}$ & $1.246^{*}$ & 1.408 & 1.380 & 1.278 & 1.500 \\
\hline Saving - 91 T Bill & $1.109^{*}$ & $1.248^{*}$ & 1.432 & 1.355 & 1.245 & 1.500 \\
\hline $\begin{array}{c}\text { Deposits - Lending } \\
\text { 95\% Confidence } \\
\text { Interval }\end{array}$ & 1.500 & $1.127^{*}$ & $0.975^{*}$ & $1.070^{*}$ & $0.947^{*}$ & $0.945^{*}$ \\
\hline
\end{tabular}

"* " indicates that the null hypothesis of a unit root cannot be rejected at the $5 \%$ level. 